\title{
Nasal abnormality and the carrier rate of Staphylococcus aureus
}

\author{
S. I. JACOBS, G. M. WILliAMSON, AND A. T. WILlis \\ From the Department of Bacteriology, School of Medicine, Leeds
}

SYNOPSIS In a group of 178 hospital nurses minor nasal abnormalities were found to be associated with an increased rate of nasal carriage of Staphylococcus aureus.

The Staphylococcus aureus is found in the anterior nares of 30 to $50 \%$ and on the skin in 12 to $25 \%$ of healthy adults (Miles, Williams, and ClaytonCooper, 1944; Williams, Blowers, Garrod, and Shooter, 1960). It is not known why some people carry the organism and others do not, although nasal carriage predisposes to skin carriage as the result of passive transfer. Despite this relationship, in about half the cases of skin carriage the organism is not found in the nose (Miles et al., 1944), neither is there any correlation between the degree of nasal colonization and the intensity and extent of contamination of the skin (Hare and Ridley, 1958).

The incidence of staphylococcal carriage is apparently random and it has been stated that neither congenital anomalies of the upper respiratory tract (Cunliffe, 1949) nor non-staphylococcal disease of the nose (Williams et al., 1960) predisposes to a higher nasal carrier rate. Although this may be true for the staphylococcus, McCartney and Harvey (1928) found that in the case of Corynebacterium diphtheriae nasal abnormality favoured the development of the carrier state. Subtle constitutional differences of the skin have been suggested as the reason for staphylococcal carriage on the integument (Tulloch, 1954) but this has not been demonstrated experimentally.

The paper records an attempt to determine some of the factors that may predispose to staphylococcal colonization of the nose and the skin in individuals without any obvious staphylococcal infection.

\section{METHODS}

One hundred and severty-eight nurses, some of whom were in the preliminary training school and had not been in contact with a hospital environment, formed the group for study.

Received for publication 2 February 1961.
CLINICAL ASSESSMENT An E.N.T. and dermatological history of each subject and her immediate family was taken. An aural surgeon examined the nose and throat in each individual and noted any clinically significant abnormality, and a dermatologist placed the subject into one of four skin types, namely, normal, dry, moist, or greasy. The presence of minor skin sepsis was also noted. A special note was made of recent treatment with chemotherapeutic agents.

BACTERIOLOGICAL SAMPLING Three swabs moistened with nutrient broth were taken from the following sites: the palmar surface of the left wrist, the nasal vestibule, and the mucosa immediately above the anterior end of the inferior turbinate. Under direct vision and with instrumentation an aural surgeon swabbed the inferior turbinate. A fourth swab was taken from the tonsillar area in the last 66 nurses.

The swabs were plated on to nutrient agar without delay. After 48 hours' incubation the plates were examined for coagulase-positive staphylococci. The phage and sensitivity patterns of these were determined. To determine sensitivity, Sentest (Evans) tablets were used on nutrient agar plates previously seeded with $1 \mathrm{ml}$. of a 1 in 100 dilution of an 18-hour broth culture.

\section{RESULTS}

The incidence of skin carriage was so low $(7 \cdot 25 \%)$ that any correlation with clinical skin types was unjustified.

The overall incidence of nasal carriage was $38 \%$ (68 out of 178). With one exception all were vestibular carriers, and in almost half $(17 \%)$ carriage extended far enough to involve the mucosa above the inferior turbinate.

The staphylococci isolated were distributed amongst all phage groups (Table I). Table I also records their susceptibility to antibiotics. It can be seen that the populations studied, with respect to the character of the staphylococci present, were 
TABLE I

CHARACTERISTICS OF STAPHYLOCOCCI ISOLATED FROM THE NOSES OF 178 NURSES

Sensitivity Patterns of Strains for

Penicillin Streptomycin Tetracycline

Erythromycin

No. of Ward Nurses Yielding Strains

of Staphylococci

\begin{tabular}{lllll}
\hline This & \multicolumn{4}{l}{ Phage } \\
$\begin{array}{l}\text { Sensitivity } \\
\text { Pattern }\end{array}$ & I & II & III & Others
\end{tabular}

No. of Preliminary Training School Nursc Yielding Strains of Staphylococci

This Phage Group

Sensitivity

Pattern

III III Others

$\begin{array}{ll}\mathbf{S} & \mathbf{S} \\ \mathbf{S} & \mathbf{S} \\ \mathbf{S} & \mathbf{S} \\ \mathbf{R} & \mathbf{S} \\ \mathbf{R} & \mathbf{R}\end{array}$

Yielding staphylococcus strains

Examined

Percentage of nurses positive

3
35
1
4
5

1
19
0
0
0

2
1
0
0

$\begin{array}{rr}0 & 0 \\ 3 & 12 \\ 0 & 1 \\ 3 & 1 \\ 5 & 0\end{array}$

0
12
1
1
0

14
6
0
0
0

6
3
0
0
0

$\begin{array}{ll}4 & 2 \\ 2 & 1 \\ 0 & 0 \\ 0 & 0 \\ 0 & 0\end{array}$

$\begin{array}{ll}2 & 2 \\ 1 & 0 \\ 0 & 0 \\ 0 & 0 \\ 0 & 0\end{array}$

${ }^{1} \mathbf{S}=$ sensitive; $\mathbf{R}^{2}=$ resistant

No strain was found to be resistant to either chloramphenicol or novobiocin.

TABLE II

PHAGE GROUP DISTRIBUTION OF STAPHYLOCOCCI ISOLATED FROM NURSES WITH NORMAL AND ABNORMAL NOSES

Nurses with

Where Stationed

No. Carrying Staphylococci of Phage Group

\begin{tabular}{llll}
\hline$I$ & II & Others
\end{tabular}

No. of

Non-carriers

Tonol

III Others

Abnormal noses

Ward

$\left.\begin{array}{l}4 \\ 0\end{array}\right\} 4$

$\left.\begin{array}{l}0 \\ 0\end{array}\right\} 0$

$\left.\begin{array}{l}3 \\ 2\end{array}\right\} 5$

$\left.\begin{array}{l}4 \\ 0\end{array}\right\} 4$

$\left.\begin{array}{l}4 \\ 3\end{array}\right\} 7$
$\left.\begin{array}{l}55 \\ 48\end{array}\right\} \begin{aligned} & 103 \\ & 110\end{aligned}$

Ward

Preliminary training school

$\left.\begin{array}{r}16 \\ 9\end{array}\right\} 25$

$6\}_{9}^{9}$

$\left.\begin{array}{l}8 \\ 1\end{array}\right\}_{14}^{9}$

$20\} \frac{12}{16}$

20

Total

comparable to those of previous workers, e.g., Barber and Burston (1955).

A clinically significant minor nasal abnormality, i.e., a deviated septum or damaged turbinate, was found in 20 individuals and of these $13(65 \%)$ carried a coagulase-positive staphylococcus in the nose. In the remainder, those having normal noses, $55(29 \%)$ were nasal carriers. The incidence of staphylococcal carriage in the group with nasal anomalies was significantly higher than that in the group with normal noses $\left(\chi^{2}=6 \cdot 88, \mathrm{n}=0.01>\mathrm{p}>\right.$ 0.001).

This relationship was further strengthened by the finding that staphylococcal carriage in the throat was almost exclusively confined to those individuals who showed some abnormality of the tonsil (Campbell, 1948). Thus, of 66 subjects examined, six had tonsillar disease and all of these carried Staphylococcus aureus in the throat. On the other hand, of the 60 subjects with normal throats only one carried a Staphylococcus aureus in this area. These findings are analogous to those of Hartley and Martin (1920), who found that the persistence of carriage of Corynebacterium diphtheriae was apparently related to the presence of diseased tonsils. In the present investigation no relationship was observed between mucosal carriage and tonsillar carriage (Dingle and Plummer, and others, 1949).

Nasal abnormality does not favour colonization of the nose by staphylococci of any particular phage 3 . group (Table II), nor does it predispose to involve- $\delta$ ment of the upper reaches of the nose (Table III).

\section{TABLE III}

EXTENT OF COLONIZATION OF NORMAL AND ABNORMAL NOSES BY STAPHYLOCOCCI

\begin{tabular}{lcccc} 
Nurses with & \multicolumn{2}{l}{ No. Carrying } & Staphylococci on/in & Total \\
\cline { 2 - 5 } & $\begin{array}{l}\text { Mucosa } \\
\text { Alone }\end{array}$ & $\begin{array}{l}\text { Mucosa and } \\
\text { Vestibule }\end{array}$ & $\begin{array}{l}\text { Vestibule } \\
\text { Alone }\end{array}$ & \\
\hline Abnormal noses & 0 & 6 & 7 & 13 \\
Normal noses & 1 & 25 & 29 & 55 \\
Total & 1 & 31 & 36 & 68
\end{tabular}

DISCUSSION

It has been stated that nothing is gained in the $\frac{?}{\mathrm{O}}$ estimation of staphylococcal carrier rates by 
swabbing the upper reaches of the nose, and indeed that misleadingly low carrier rates may be obtained by so doing (Williams et al., 1960). Stratford et al. (1960), however, isolated Staphylococcus aureus from mucosal swabs in $51 \%$ of a group of 103 patients but from vestibular swabs taken from the same group in only $34 \%$, a result that throws some doubt on the obvious criticism of mucosal sampling that the organisms isolated might be contaminants derived from the vestibule. The technique used by Stratford, Rubbo, Christie, and Dixson (1960) is not detailed; in our tests the vestibule was opened out with a Thudichum speculum and samples taken from the clearly visualized inferior turbinate region. In our experience the mucosa is rarely involved alone.

In view of the findings of Cunliffe (1949), who found no increase in the staphylococcal carriage rate of children with gross abnormality of the nasopharynx, our finding that there is a higher rate of nasal carriage in nurses with minor nasal abnormalities might appear surprising, However, this result for the staphylococcus is in accord with that of McCartney and Harvey (1928) for Corynebacterium diphtheriae, who found that $72 \%$ of diphtheria carriers showed nasal abnormalities, in contrast to patients who had recovered clinically from diphtheria and were also bacteriologically free in whom the abnormality rate was only $7 \%$. Moreover in the discussion on the epidemiology of scarlet fever, Wilson and Miles (1955) suggest that abnormalities of the upper respiratory tract prolong carriage of Streptococcus pyogenes.

We are indebted to Dr. S. T. Anning, consultant dermatologist, Mr. T. McM. Boyle, consultant aural surgeon, the matron, nursing staff of the E.N.T. Department, and the nurses of the General Infirmary at Leeds, for their kind cooperation. We should also like to thank Drs. G. B. Ludlam and I. O. Stewart for their assistance with the phage typing.

\section{REFERENCES}

Barber, Mary, and Burston, J. (1955). Lancet, 2, 578.

Campbell, A. C. P. (1948). J. Path. Bact., 60, 157.

Cunliffe, A. C. (1949). Lancet, 2, 411.

Dingle, J. H., and Plummer, N., and others (1949). Amer. J. Hyg., 50, 331.

Hare, R., and Ridley, M. (1958). Brit. med. J., 1, 69.

Hartley, P., and Martin, C. J. (1920). Proc. roy. Soc. Med., 13 (Sect. Epidem.), 277.

McCartney, J. E., and Harvey, W. C. (1928). Ibid, 21, 845.

Miles, A. A., Williams, R. E. O., and Clayton-Cooper, B. (1944). J. Path. Bact., 56, 513.

Stratford, B., Rubbo, S. D., Christie, R., and Dixson, S. (1960). Lancet, 2, 1225.

Tulloch, L. G. (1954). Brit. med. J., 2, 912.

Williams, R. E. O., Blowers, R., Garrod, L. P., and Shooter, R. A. (1960). Hospital Infection, Ch. 3. Lloyd-Luke, London.

Wilson, G. S., and Miles, A. A. (1955). Topley and Wilson's Principles of Bacteriology and Immunity, 4th ed., Vol. 2, p. 1666. Arnold, London. 